\title{
The review of 'mining' in Russian media
}

\author{
Anastasiia Pachina ${ }^{1}$ \\ Anastasiia Popova
}

National Research University 'Higher School of Economics', Russia

DOI: 10.30547/worldofmedia.2.2019.2

\begin{abstract}
In 2017, there was a sharp increase in the number of publications on the subject of 'mining' in Russian non-core media, which indicates the increased interest among non-professional audiences. This study relates the practice of mining crypto-currencies to the category of 'unobtrusive' issues. It gives the media the role of translator, which shapes public opinion. The purpose of this work is to identify the context in which the discussion about the 'mining' in noncore Russian media is immersed. Based on different sources, we conducted a quantitative content analysis and used joint mentions of categories on the topic of 'mining' to build the network analysis. Moreover, interviews with 'miners' were used for more correct interpretation. The results showed that the non-core Russian media pay close attention to the category of 'regulation' of 'mining', which is most often mentioned with the Central Bank and the President. Besides, the geographical specifics of 'mining' are focused mostly on Moscow, Moscow region, the cities of Siberia and some foreign countries (the USA, China). The analysis also showed that the presence and tightness of category links in the subject of 'mining' have common features with the concentration of Bitcoin nodes.
\end{abstract}

\section{Keywords}

Mining, cryptocurrency, bitcoin, discussions in the media, economics in the media, network analysis, network of mutual mentions.

\section{Introduction}

'Mining' has already been called the gold rush of the 21st century: the media fix an acute shortage of 'shovels' - video cards in electronics stores (Kodachigov,

Corresponding author:

Anastasiia Pachina, Faculty of Social Sciences, National Research University 'Higher School of Economics', 20 Myasnitskaya ulitsa, Moscow, Russia.

Email: pachinaanastasiya@mail.ru, anastasiia.popova.s@gmail.com 
2017). According to CoinDesk (www.coindesk.com), the rate of Bitcoin, the most popular cryptocurrency, in July 2010 was \$ 0.06, in the beginning of December 2017 it already reached \$ 18,000. Google trends for the dynamic of the Bitcoin popularity showed that the statistics of queries on the Internet of the word 'bitcoin' since late November 2017 jumped from 30 points to 100.

Satoshi Nakamoto, the creator of Bitcoin, in his work, explaining the principles of the functioning of this technology as an electronic means of payment, paid particular attention to stimulation. Due to the decentralization, the motivation for supporting the network is provided by remuneration in the form of a cryptocurrency: 'the constant addition of the constant of the number of new coins is analogous to the resources used by gold diggers to add gold to circulation. In our case, this is CPU time and electricity' (Nakamoto, 2009: 4). The 'miners' are people whose task is to maintain the system, which is expressed in the duty of confirming transactions, adding new blocks to the Blockchain, and introducing new bitcoins (or any other cryptocurrency). 'Miners' receive cryptocurrency as a reward when they manage to decipher a special mathematical function - a hash; the production process itself is called 'mining'.

The subject of the analysis, the review of 'mining' in non-core media, emerged as a result of interviews with 'miners'. We found out that the scenarios for obtaining primary information on both the Blockchain area and the cryptocurrency, in general, and on 'mining', in particular, can be divided into three categories: media, family and work colleagues (business partners). In addition, the tendency of the 'miner' to self-education is also expressed in the collection of information, literally 'bit by bit', from a variety of sources, including the media.

Following the research conducted by the NAFI Research Centre, in 2017 only $1 \%$ of the Russian population had experience in using cryptocurrencies. Since 2015, this figure has increased from $0 \%$ to $1 \%$. The experience of using cryptocurrency is a broader concept than the mining process, so it can be assumed that mining is occupied by an even smaller part of Russia's population.

However, it is worth noting that despite a slight increase in the experience of using cryptocurrencies in two years, 2017 year is characterized by a sharp leap in media materials at the request of 'Mining' among all Russian media, including television, print media, Internet sources, radio air: if in 2016 there were only 21 of them, in 2017 the number increased to 488 (Figure 1) (Requested in a Factiva resource), that makes the interest in 'mining' in Russia the specificity of 2017. 


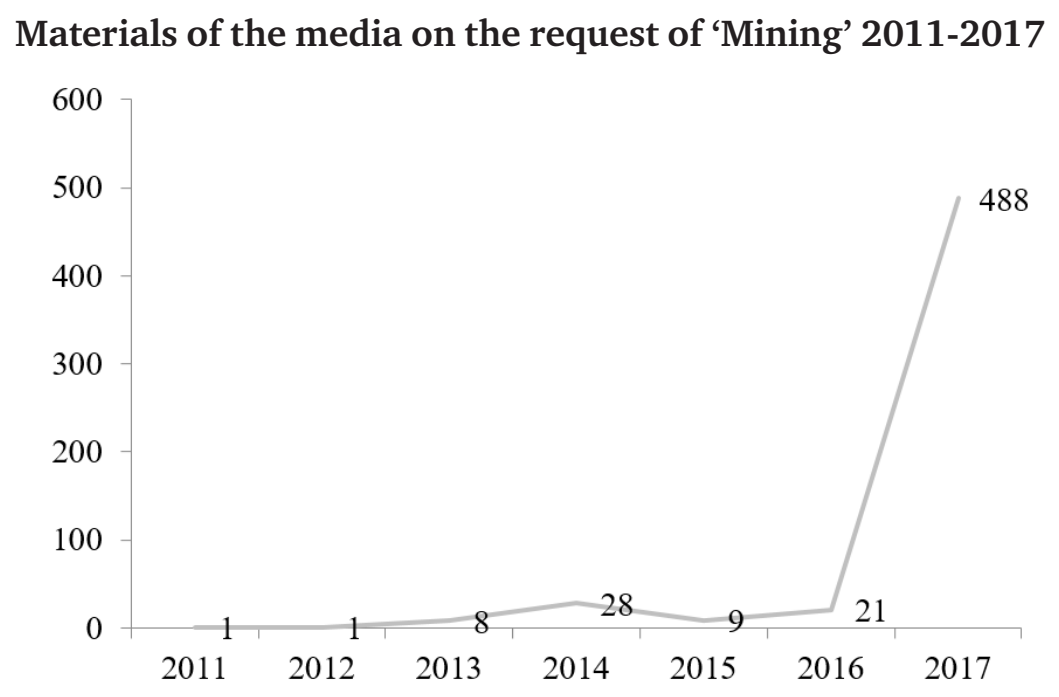

Despite the fact that the 'mining' at the end of 2017 is not yet defined in the Russian legislation, the fact of investing in equipment for 'mining', the ability to generate income and entrepreneurial activities allows us to connect this practice not only with the development of technology, but also with economic activities that generate economic discussions.

Economic discussions in the media affect the behavior of people and their perception of reality (Kazun, 2017: 98-99). However, even if there is a desire for the population to be aware of the economic situation, only $38 \%$ of Russians believe that economic news is fairly objective, according to the research of VCIOM (Russian Public Opinion Research Center) 'Media consumption today', which was conducted in 2017. Moreover, the real state of affairs in the economy, their media coverage and public opinion on these issues do not always coincide.

Studies also show that due to the complexity of translating of objective economicindicators into subjective assessments theeconomy is a complex topicfor discussion (Holbrook, Garand, 1996: 351-375). In this situation, the mass media take on the complex role of the translator, which should, in an understandable form, bring the news to the reader. However, economically focused topics can be ignored by the media, as information can be incomprehensible to the audience, and journalists often do not have the necessary knowledge (Manning, 2013). An example of such fragmentation of economic news is the extremely low media attention to the situation in the markets of debt instruments and derivatives at the threshold of the financial crisis of 2008 (Tett, 2009). 
It would seem that in the case of 'mining' the incompleteness of information should not arise. There are a number of online publications that specialize in cryptocurrency and blockchain technologies, such as Forklog, DeCenter, Cointelegraph and others. According to the rating of Medialogy (www.mlg.ru), www.forklog.com, the online resource, ranks eleventh in the top-20 most cited media of the financial sector for 2017. In top-15 economic channels Telegram on views, four are devoted to the topic of cryptocurrencies.

However, the discussion on the cryptocurrency has already gone beyond the framework of a purely professional community and often seeps into the agenda of popular media. Focusing on a wide audience, the media are forced to adapt information and select the most interesting stories. In our work, we concentrate on non-core media, on those sources of mass information that do not specialize in the materials of cryptocurrency and blockchain technology. Due to the fact that most of the population has no personal experience in this area, materials about 'mining' can be classified as 'unostentatious' issues. In this case, the media are almost the only source of information on this issue and directly affect the formation of public opinion (McCombs et al., 1981).

The purpose of our work is to identify the people and institutions involved in the discussion about 'mining' in non-core Russian media and to reveal the general context in which the discussion is immersed, provided that the majority of the Russian population does not have personal 'mining' experience. We highlight the most popular categories covering the topic of 'mining' in non-core media and focus on the correlation of the received categories, on their links and mutual mentions.

\section{Methodology}

In our study, we used the resource Factiva. Around 1,500 Russian-language materials on mining were downloaded during the period from January 1, 2011 to December 12, 2017. Then, using the Yoshikoder program, we identified categories (see Appendix, Table 1) and carried out quantitative content analysis or frequency allocation of mentions. The frequency of mentions is sorted in descending order, which made it possible to emphasize the most popular words in network analysis.

In the study, we used media materials from all regions of Russia, not limited to a specific locality, as we assume that 'mining' is a new practice for Russia, which is concentrated not only in Moscow, but also in other regions of the country. We focused on television news releases and information messages in print media, online sources and radio air. 
In addition to the quantitative method of estimating the frequency of mentioning the selected categories with Yoshikoder, we used the network analysis. To visualize network analysis, we applied Gephi software, which creates the image in terms of the pairwise correlations. The main focus of network analysis is the comprehension and interpretation of social reality as an integral picture through interconnected multiple nodes (words, schemes, frames) (Kaplan, 1973: 66). Network analysis allows the viewer to see which provisions have the received categories, whether their positions are similar and how categories are 'embedded' in the overall network (Hanneman, 2005: 4). Categories can be identified as public themes, political candidates and consumer brands (McCombs, 2001: 69). Over the past few years, the network analysis method has been used to study the interaction between news groups (Choi, 2002), the personalities of television shows, television channels and websites (Fine, 1981).

People create connections in social networks between each other with the help of the likes (Xiaolong, 2014: 91). Similar to 'mutual likes' a network connecting events and personalities is modeled through the mutual mentions in the media. Thus, network analysis focuses on the relationship between categories, rather than on individual actors and their attributes (Hanneman, 2005: 4).

In our study, the categories are presented by neutral words: countries, individuals, state structures, and by emotionally colored words. To find 'emotions' in the text, we compiled a dictionary of positively and negatively colored words with the help of quantitative content analysis (Thelwall, 2010: 2547). The dictionary included three emotionally colored categories: legalization, regulation and violation. In addition, we had the opportunity to confirm or deny certain types of communication through the materials of personal interviews with those who are engaged in the mining of cryptocurrency - 'miners'.

\section{Results}

The most frequently published articles in the Russian media about the cryptocurrency contain information relating to Russia, which is predictable. Events in the country (or with its participation) generally attract media attention because they can influence the population. Hence, this news is wittingly more interesting. However, other countries such as the United States, Japan and China are often mentioned in the discussion about cryptocurrencies in Russian media (Table 1). 
Frequency of mentions of the countries in articles about 'mining'

\begin{tabular}{|c|c|}
\hline Country (group of countries) & Frequency \\
\hline Russia & 466 \\
\hline USA & 245 \\
\hline Japan & 104 \\
\hline China & 77 \\
\hline Switzerland & 38 \\
\hline CIS & 22 \\
\hline Hong Kong & 13 \\
\hline Korea & 11 \\
\hline
\end{tabular}

The presence or absence of a foreign country in the news agenda can be explained in three ways: national characteristics (the size of the country and its economic and political power of influence in the international arena), connectivity (geographical, demographic and other affinity with the country) (Sheafer et al., 2013: 1256-1276). Finally, by events, for example, natural disasters, wars, conflicts. Thus, the presence of the United States, Japan and China in Russian articles on 'mining' may be explained by the significant influence of these countries in this area of study while, for example, CIS countries have regular contacts with Russia.

In addition, some of the identified countries were also mentioned in one of the interviews in the question of the right regulation of 'mining': '... countries are heterogeneous, and one of them will ban, the others will not. For example, Japan has allowed, as well as Australia; in the United States some people are thinking whether to allow or prohibit' (Oleg, 'Miner').

In another interview, China was mentioned during a talk about purchasing of equipment for 'mining'. In addition, both informants noted that everything is produced exclusively in China. They buy it either through the intermediary or through intermediaries. 


\section{The presence of Bitcoin network connections} in the world, 2015

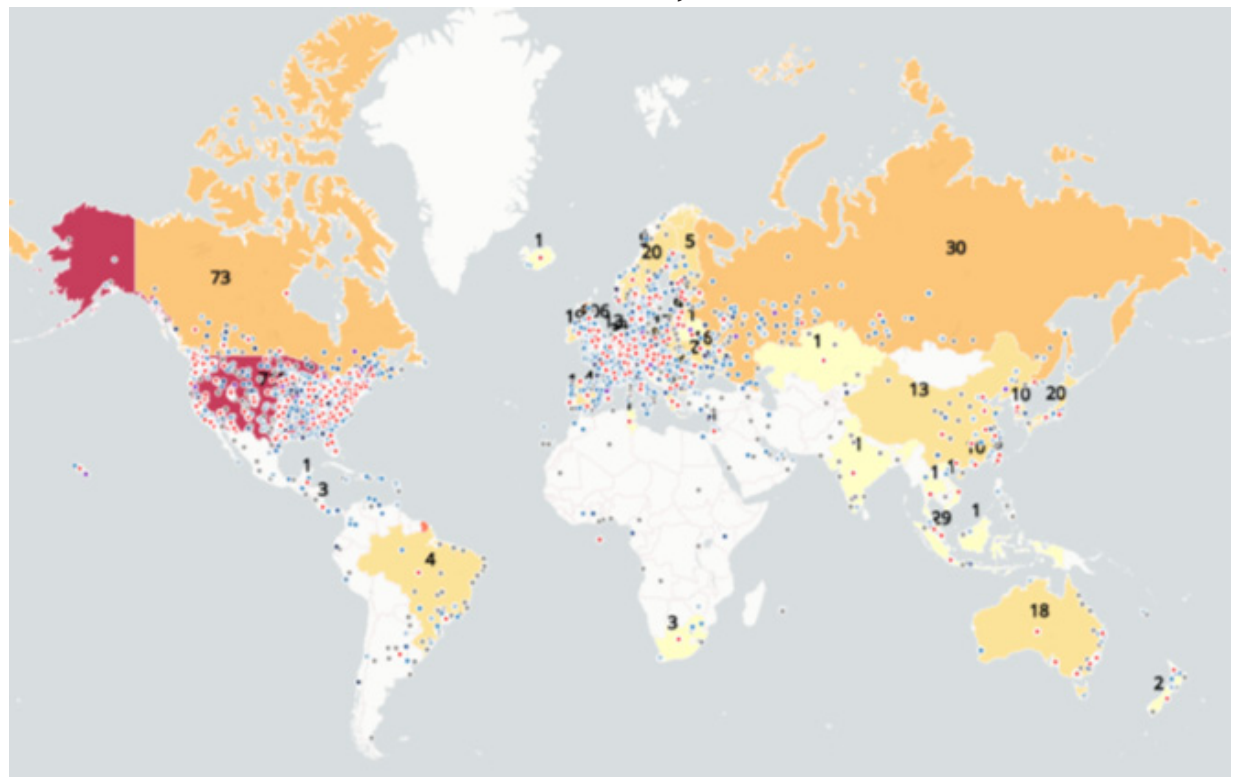

Source: https://timeknows.carto.com

As one can see in Figure 2, countries such as the USA, Russia, Japan and China, and also European countries, partly Australia and Latin America are concentrating the Bitcoin nodes. The counting data is based on four types of nodes: Wallet, 'Miner', Full Blockchain and Network Routing. Thus, despite the trait of over-territoriality, the cryptocurrency still has a geographic specificity. And the media pay special attention to countries that have significant influence in this area, as well as to countries where significant changes take place in the legal regulation of the cryptocurrency market. In general, the mass media are more likely to focus on changes of the situation (Soroka et al., 2015), which explains the attention of Russian media to countries introducing new bans on such activities, or, on the contrary, resolving some of its aspects.

Another point is the frequency of mentions of Russian cities (Table 2). We assumed that 'mining' is a specificity of Central region of Russia. However, this phenomenon is not only specific to the capital region. According to contentanalysis of media, Irkutsk, St. Petersburg and Novosibirsk are mentioned quite often. 
Cities of Russia and frequency of mentions

\begin{tabular}{|c|c|}
\hline City & Frequency \\
\hline Moscow and Moscow region & 245 \\
\hline Irkutsk & 50 \\
\hline St. Petersburg & 27 \\
\hline Novosibirsk & 23 \\
\hline
\end{tabular}

Similar conclusions about the involvement cryptocurrencies discourse of various regions of Russia can be arrived at and based on the statements of informants:

1) 'I'm sure there is a lot of concentration in Moscow region. Because it is possible to steal electricity and therefore, that there are a lot of abandoned warehouses, mini-factories, these are other premises. For example, in the Vladimir region. Well, very much in Siberia, because it's just cold, you do not need to spend additional money on air conditioning' (Eugene, 'Miner').

2) 'I think there are many in Moscow. Well, in the regions, too. Now the Irkutsk region is known' (Oleg, 'Miner').

Figure 3

The presence of Bitcoin network connections in Russia, 2015

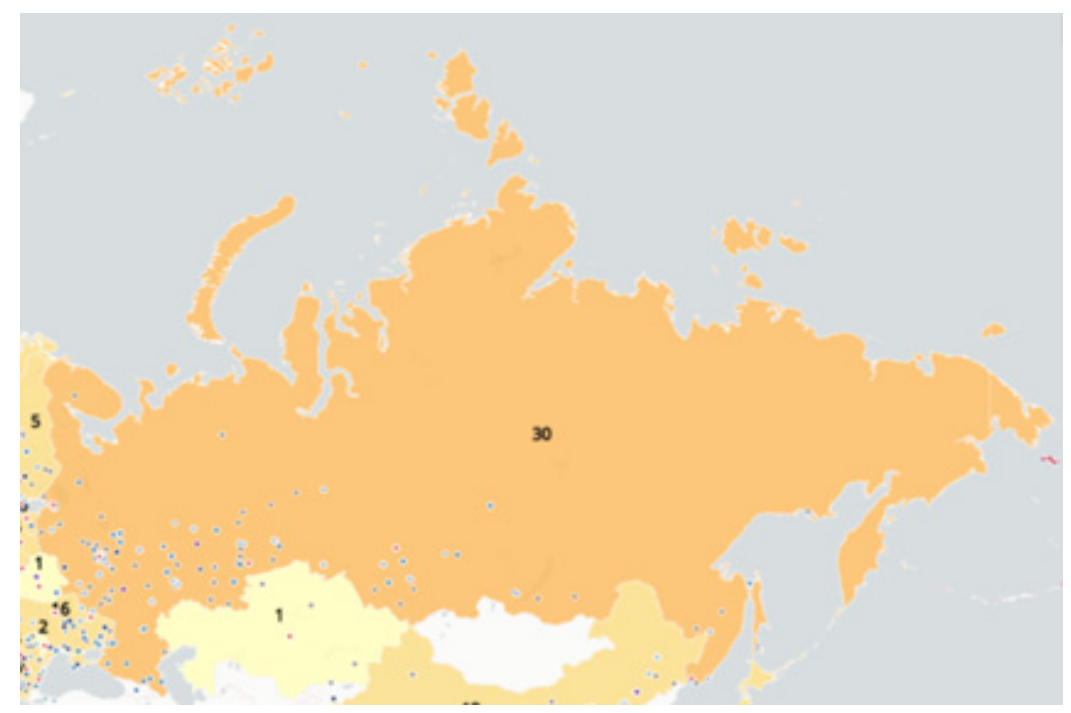

Source: https://timeknows.carto.com 
We can find out that there is a concentration in the Central and Siberian federal districts.

Moreover, according to the results of content analysis, it is possible to identify top- 3 personalities by frequency in the news of Russian media: Dmitry Marinichev (Internet ombudsman), Satoshi Nakamoto (creator of Bitcoin) and Vitalik Buterin (creator of Etherium, the second most popular cryptocurrency in the world (Table 3 ).

Table 3

Personalities and frequency of mentions

\begin{tabular}{|c|c|}
\hline Personality & Frequency \\
\hline Marinichev & 195 \\
\hline Nakamoto & 80 \\
\hline Butterin & 63 \\
\hline Nabiullina & 45 \\
\hline Latypov & 38 \\
\hline Massukh & 38 \\
\hline Nikiforov & 35 \\
\hline Radchenko & 35 \\
\hline Vinogradov & 33 \\
\hline Smerkis & 32 \\
\hline Gref & 30 \\
\hline Trutnev & 24 \\
\hline Medvedev & 19 \\
\hline Oskyn & 8 \\
\hline Sydorenko & 8 \\
\hline
\end{tabular}

The interview with the 'miners' confirms the involvement of the Internet ombudsman Marinichev in the discussion about the 'mining' in the Russian media:

1) '.. there is an ombudsman $<\ldots>$ our Internet in Russia, here, he is very hard engaged in "mining" himself' (Eugene, 'Miner').

2) 'Marinichev, adviser to the President in the sphere of Internet rights or whatever it is, I do not know <...> In my opinion, he has a "mining" equipment there (in the southeast of Moscow, - note). Of course, I do not know, I have inaccurate data. <...> This is from the media' (Oleg, 'Miner').

Their opinions on 'mining' are also expressed by the political institutions and the Central Bank. Table 4 demonstrates that the largest number of references 
refers to the Central Bank, the next position in the rating belongs to the Government, then to the Ministry of Finance.

Table 4

Political institutes and the Central Bank

\begin{tabular}{|c|c|}
\hline Title & Frequency \\
\hline CB & 217 \\
\hline Government & 141 \\
\hline Ministry of Finance & 126 \\
\hline President & 114 \\
\hline The State Duma & 53 \\
\hline
\end{tabular}

Table 5 shows the number of mentions of various media in the articles on 'mining' where the absolute leader is RBC.

Table 5

Media and frequency of mentions

\begin{tabular}{|c|c|}
\hline Media & Frequency \\
\hline RBC & 258 \\
\hline Vedomosti & 149 \\
\hline Meduza & 14 \\
\hline Kommersant & 63 \\
\hline Novaya gazeta & 3 \\
\hline
\end{tabular}

It is worth noting that it was RBC, the only Russian media, that was listed by one of the informants as the direct source of information on the topic of 'mining' and the sphere of cryptocurrencies. The attention of certain media sources to the 'mining' can be explained by the complexity of the topic.

\section{Network of mutual mentions}

The answer to the question about what categories the discussion about 'mining' in Russian media are more popular is in Figure 4. 
Figure 4

The most popular categories on the subject of 'mining'

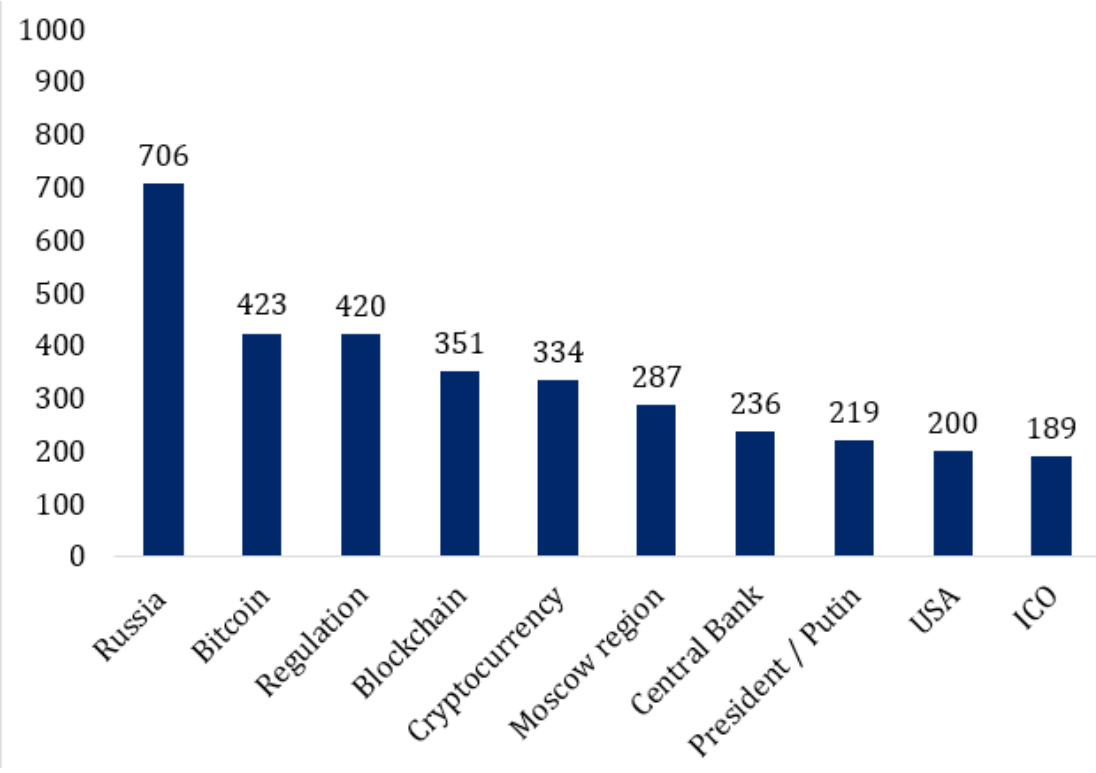

Based on this diagram, we can conclude that the geographic (Russia, Moscow region, the USA) and decentralized technologies (Bitcoin, Blockchain, Cryptocurrency, ICO) contexts are quite common.

Moreover, to analyze the connection of key categories, we have built a network of mutual mentions of the topic of 'mining' in Russian media (Figure 5). A similar method has already been used in a number of studies (Guo \& Vargo, 2015; Guo et al., 2015; Kazun, 2017; Vu et al., 2014). The categories that are closest to 'mining' mentioned together with the topic of cryptocurrency more often. 


\section{A network of mutual mentions of the topic of 'mining' with key categories in the materials of television news releases, information messages in print media, Internet sources and radio air}

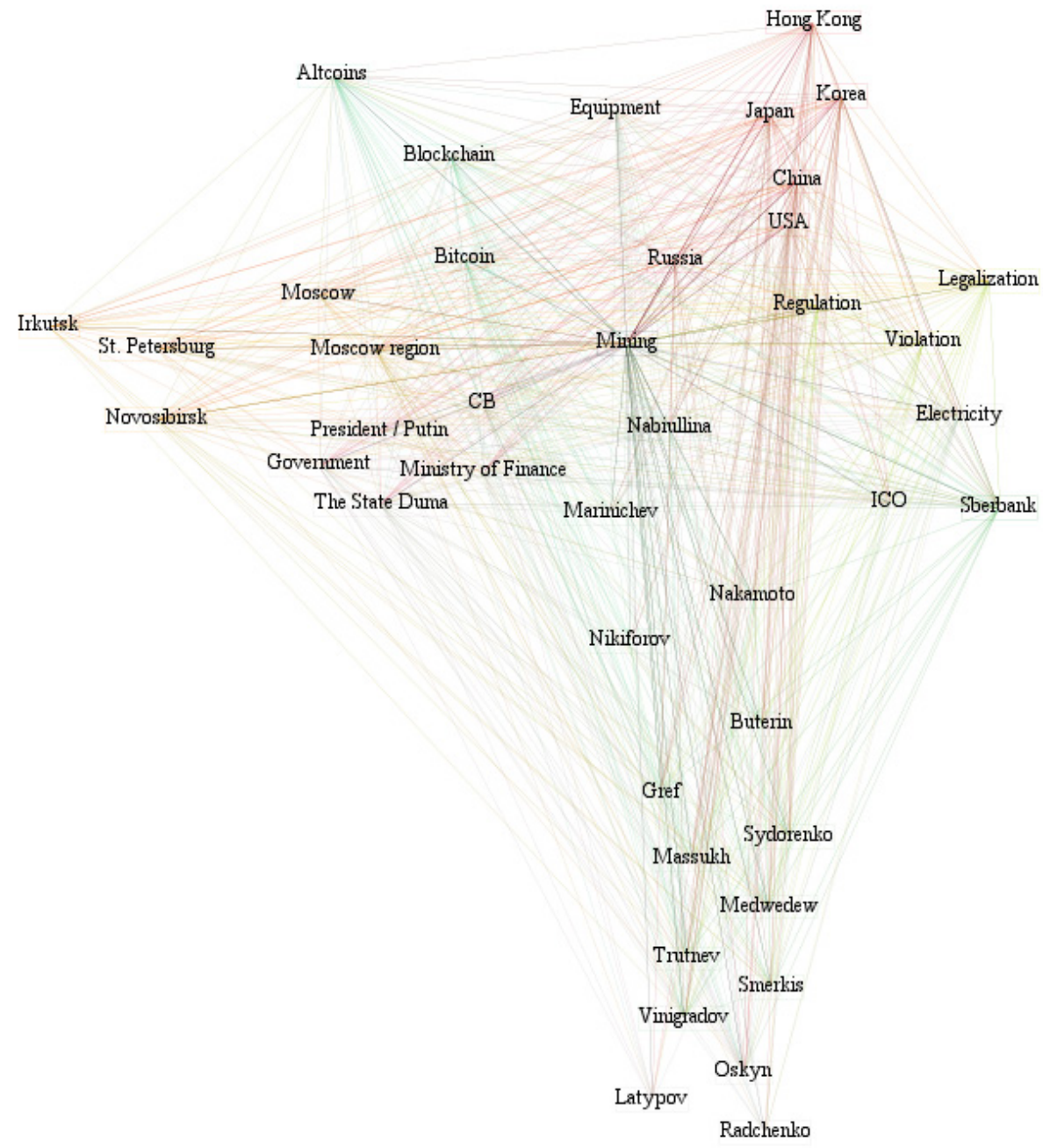

The figure is made by the authors using the Gephi software

As it was noted earlier, the 'mining' is still outside the legal field (the beginning of December 2017), but the frequency of the category related to regulation (which includes regulation, law, legislation, control, tax, taxation) means the propensity of the discussion regulation in media. 
In contrast, there is a thought among 'miners' that 'mining' as well as the whole Blockchain sphere cannot be a priori adjusted: 'We can adopt a law on how the moon should move. But saying this to the moon is a bit redundant. It will move as it did. No one can influence the movement of the moon. No one can adjust this movement. The same is here' (Alexandr, Blockchain specialist and 'miner').

There are also several reasons why states want to take control of digital currency. There is a risk that people may become victims of fraudsters (scammers) and Ponzi schemes. Also, the cryptocurrency provides opportunities for money laundering, hiding income from the tax service and making transactions with illegal goods (Turpin, 2014).

In addition, the media pay a lot of attention to the Central Bank in this case. The explanation is that this institute has the monopoly on money issue. The fundamental characteristic of Bitcoin is full decentralization - the principle of a peer-to-peer network, which in fact means no influence on Bitcoin from the public or private level. This makes Bitcoin independent from issuing centers (Butenko, 2014). These characteristics can also argue the importance of the figure of the Russian president, and his greatest connection with the category of regulation (269 mutual mentions).

The discussion about the "mining" is relevant for the Central Bank and the Ministry of Finance, therefore, we considered their mutual mentions with emotional categories (legalization, violation, regulation). The Central Bank is more immersed in the discussion about mining than the Ministry of Finance (236 and 151 mutual mentions with mining, respectively). For the Central Bank, regulation is the most popular category with which it has the highest percentage of mutual mentions $(8.95 \%$ of the total), violation $(1.32 \%)$ is in the second place, legalization $(0.64 \%)$ is the least popular. For the Ministry of Finance, regulation is also the most popular category (8.64\%). However, despite the obvious urgency of the issue of the 'mining' legal status, the relationship between emotionally colored categories and the most interested in this issue state structures is almost imperceptible.

From interviews with the 'miners' it was found out that the equipment is most often supplied from China, but the number of mutual mentions showed that the equipment category has a closer connection with the USA and Hong Kong (64 and 35 mutual mentions respectively) than with China (2 mutual mentions).

In addition, the discrepancy with the materials of the interview is observed in a situation with regional specifics, which is interesting with such a phenomenon as 'cryptotourism'. It describes the location of 'mining' equipment for the 
production of cryptocurrencies in the most profitable regions for mining. For example, Irkutsk and Novosibirsk regions attract 'miners' due to cheap electricity, which is confirmed by the materials of the interview. However, the analysis of the number of mutual mentions showed that the phenomenon of 'mining' is more closely connected with Moscow region and Moscow (287 and 188 mutual mentions respectively) than with St. Petersburg (35 mutual mentions).

\section{Conclusion}

Over the past year, the phenomenon of 'mining' has become one of the most highprofile events in the technological and economic spheres. The words 'bitcoin', 'cryptocurrency' have long gone beyond the profile of economic publications and leaked into the socio-political sources of information that set the agenda.

Because of the content analysis of the media, we identified the most popular categories in the subject of 'mining'. Further, the most mentioned countries and cities of Russia are identified. It is worth noting that certain people and organizations are involved in the subject of the extraction of cryptocurrency, both governmental structures and private entrepreneurs. In addition, it is important to note that the category of 'regulation', which includes the words 'taxes', 'laws' and 'control' is the third by number of mentions, which means close attention to this topic in the socio-political debate around the phenomenon of 'mining'.

Network analysis showed that the discussion in the media on some issues is different from the information received from the 'miners'. So, the equipment, which comes mainly from China (as informants said), as a category in the media is practically not connected with it. The same is observed in the context of the regions of Russia.

In this study, quantitative analysis of the frequency of references was used to identify the categories required for the research. That is, the topics for analysis were taken from real data. Moreover, for a more substantive interpretation, we used interview materials with 'miners'. They are the direct carriers of this practice and experts, since their activities are the object of media publications. This allowed us to look at the situation from various sides. The research makes it possible to understand the involvement and influence of different persons and institutions in a cryptocurrency sphere that could allow adopting strategies and laws in this digital financial issue.

In our study, we used non-core Russian media to analyze the ongoing discussion about mining, provided that the majority of the Russian population has no experience in interacting with cryptocurrency. In the future it is worthwhile to consider publications that specialize on the cryptocurrency and the process of 
its extraction in order to recreate the full picture of the relationships in the new phenomenon that swept the society.

\section{References}

BUTENKO, E. D. (2014). Bitkoyn. Sostoyaniye i perspektivy razvitiya kriptovalyutyю [Bitcoin. Condition and perspectives for cryptocurrency development]. Finance \& Credit, 23(599), pp. 44-47.

CHOI, J. H. \& DANOWSKI, J. (2002). Making a global community on the netglobal village or global metropolis? A network analysis of USENET newsgroups. Journal of Computer Mediated Communication, 7(3).

Cryptocurrencies: Not the money of the future yet, but already a fashionable phenomenon (2017). NAFI Research Centre. Available from: https://nafi.ru/ analytics/kriptovalyuty-eshchye-ne-dengi-budushchego-no-uzhe-modnoeyavlenie/ [Accessed 24th November 2018].

EVGENIY (2017). The review of 'mining' in Russian non-core media. [Interview]. 31st October, 2017.

FINE, M. G. (1981). Soap opera conversations: The talk that binds. Journal of Communication, 31, pp. 97-107.

GUO, L. (2012). The application of social network analysis in agenda setting research: A methodological exploration. Journal of Broadcasting \& Electronic Media, 56(4).

HANNEMAN, R. A. \& RIDDLE, M. (2005). Introduction to social network methods. Riverside, CA, University of California.

HOLBROOK, T. \& GARAND, J. (1996). Homo economicus? Economic information and economic voting. Political Research Quarterly, 49(2), pp. 351-375.

KAPLAN, S. (1973). Cognitive maps in perception and thought. In: R. M. Downs \& D. Stea, Image and environment: Cognitive mapping and spatial behavior. Chicago, IL, Aldine. pp. 63-78.

KAZUN, A. D. (2017). Kak ekonomika v novostyakh vliyayet na novosti v ekonomike? Obzor teoriy o spetsifike i roli ekonomicheskikh diskussiy v SMI [How does economy in the news affect the news in economy? A review of theories on the specific features and the role of economic discussions in the media]. Economic Sociology, 18(3), pp. 97-129.

KODACHIGOV, V. V. (2017). V Rossii voznik ostryy defitsit videokart. [An acute shortage of video cards has occurred in Russia]. Vedomosti, 19th June, 2017. Available from: https://www.vedomosti.ru/ technology/articles/2017/06/19/695005-rost-kursa-kriptovalyut?utm_ source $=$ browser\&utm_medium $=$ push\&utm_campaign $=$ push_notification [Accessed 10th January 2018]. 
MCCOMBS, M. \& GHANEM, S. (2001). The convergence of agenda setting and framing. In: S. Reese, O. Gandy \& A. Grant, Framing public life. Mahwah, NJ, Erlbaum, pp. 67-81.

MCCOMBS, M., GRABER, D. \& WEAVER. D. (1981). Media agenda-setting in the presidential election. NY, Praeger Scientific.

NAKAMOTO, S. (2008). Bitcoin: A peer-to-peer electronic cash system. Available from: https://bitcoin.org/bitcoin.pdf [Accessed 8th December 2017].

OLEG (2017). The review of 'mining' in Russian non-core media. [Interview]. 1st November, 2017.

SHEAFER, T, BEN NUN, P. \& SHENHAV, S. (2013). The conditional nature of value-based proximity between countries: Strategic implications for mediated public diplomacy. American Behavioral Scientist (ABS), 57(9), pp. 1256-1276.

THELWALL, M., BUCKLEY, K., PALTOGLOU, G., CAI, D. \& KAPPAS, A. (2010). Sentiment strength detection in short informal text. Journal of the American Society for Information Science and Technology, 61(12), pp. 2544-2558.

TURPIN, J. B. (2014). Bitcoin: The economic case for a global, virtual currency operating in an unexplored legal framework. Indiana Journal of Global Legal Studies, 21(1). Available from: https://www.repository.law.indiana.edu/ ijgls/vol21/iss1/13 [Accessed 17th November 2017].

XIAOLONG SONG, XIANGBIN YAN \& YUMEI LI (2014). Modelling liking networks in an online healthcare community: An exponential random graph model analysis approach. Journal of Information Science, 41(1), p. 89-96.

\section{Appendix}

Table 1

List of informants

\begin{tabular}{|c|c|c|c|c|c|c|c|}
\hline \#No & Name & Gender & Age & City & Mining & $\begin{array}{c}\text { Interview } \\
\text { location }\end{array}$ & Date \\
\hline 11 & Evgeniy & Male & 23 & Moscow & $\begin{array}{c}\text { primary } \\
\text { activity }\end{array}$ & skype & 31.10 .2017 \\
\hline 22 & Oleg & Male & 42 & Moscow & $\begin{array}{c}\text { concurrent } \\
\text { activity }\end{array}$ & café, Moscow & 01.11 .2017 \\
\hline 33 & Alexandr & Male & 32 & Moscow & $\begin{array}{c}\text { concurrent } \\
\text { activity }\end{array}$ & $\begin{array}{c}\text { office of the } \\
\text { informant, } \\
\text { Moscow }\end{array}$ & 12.04 .2017 \\
\hline
\end{tabular}

